\title{
Impact of the COVID-19 Crisis on Work and Private Life, Mental Well-Being and Self-Rated Health in German and Swiss Employees: A Cross-Sectional Study
}

Martin Tušl ( $\nabla$ martin.tusl@uzh.ch )

University of Zurich

\section{Rebecca Brauchli}

University of Zurich

Philipp Kerksieck

University of Zurich

\section{Georg Bauer}

University of Zurich

\section{Research Article}

Keywords: COVID-19, logistic regression, work life, private life, mental well-being, self-rated health, Germany, Switzerland

Posted Date: January 13th, 2021

DOl: https://doi.org/10.21203/rs.3.rs-141755/v1

License: (c) (1) This work is licensed under a Creative Commons Attribution 4.0 International License. Read Full License

Version of Record: A version of this preprint was published at BMC Public Health on April 17th, 2021. See the published version at https://doi.org/10.1186/s12889-021-10788-8. 


\section{Abstract}

Background: The COVID-19 crisis has radically changed the way people live and work. While most studies have focused on prevailing negative consequences, potential positive shifts in everyday life have received less attention. Thus, we examined the actual and perceived overall impact of the COVID-19 crisis on work and private life, and the consequences for mental well-being (MWB), and self-rated health (SRH) in German and Swiss employees.

Methods: Cross-sectional data from 2,118 German and Swiss employees (18-65 years) were collected. Using logistic regression, we analyzed how sociodemographic factors and the actual changes in work and private life routines were associated with participants' perceived overall impact of the COVID-19 crisis on work and private life. Moreover, we explored how the perceived impact and the actual changes were associated with MWB and $\mathrm{SRH}$.

Results: About $30 \%$ of employees reported that their work and private life had worsened, whereas about $11 \%$ reported improvements in work and $14 \%$ in private life as a result of the crisis. Mandatory short-time work was strongly associated with perceived negative impact on work life, while work from home, particularly if experienced for the first time, was strongly associated with a perceived positive impact on work life. Concerning private life, younger age, living alone, reduction in leisure time, and changes in quantity of caring duties were strongly associated with perceived negative impact on private life. In contrast, living with a partner or family, short-time work, and increases in leisure time and caring duties were associated with perceived positive impact on private life. Perceived negative impact of the crisis on work and private life was associated with lower MWB and SRH. Moreover, perceived positive impact on private life was associated with higher MWB. Finally, mandatory shorttime work was negatively associated with MWB and SRH, and an increase in leisure time was positively associated with MWB and SRH.

Conclusion: The results of this study show the differential impact of the COVID-19 crisis on people's work and private life as well as the consequences for MWB and SRH. This may inform target groups and situation-specific interventions to ameliorate the crisis.

\section{Background}

On January 30, 2020, the World Health Organization (WHO) declared the outbreak of COVID-19 a Public Health Emergency of International Concern (PHEIC) [1]. In the following weeks, the virus quickly spread worldwide, forcing the governments of affected countries to implement lockdown measures to decrease transmission rates and prevent the overload of hospital emergency rooms. Consequently, much of the working population suddenly faced drastic changes to everyday life. People who commuted to work and had rich social lives outside their homes found themselves in a mandatory work from home (WFH) situation, many employees were furloughed or laid off as various businesses and industries had to shut down, and health workers in emergency rooms as well as supermarket staff and other essential employees were faced with a dramatic increase in workload and job strain $[2,3]$.

Regarding the public health impact of the COVID-19 crisis, several studies suggest that working conditions have deteriorated and that employees are more likely to experience mental health problems, such as stress, depression, and anxiety [4-7]. In particular, women, young adults, people with chronic diseases, and those who have lost their 
jobs as a result of the crisis seem to be the most affected [7-10]. One of the common stressors that research has highlighted is the fear of losing one's job and, consequently, one's income [3]. Moreover, social isolation, conflicting messages from authorities, and an ongoing state of uncertainty have been described as some of the main factors contributing to emotional distress and negatively affecting mental health and well-being $[4,10-13]$.

In the European context, Eurofound [8] released a report on research in April 2020 involving 85,000 participants across $27 \mathrm{EU}$ member countries. The data indicate that the EU population experienced high levels of loneliness, low levels of optimism, insecurity regarding their jobs and financial future, as well as a decrease in well-being. Germany scored slightly below the EU27 average in well-being, and there is further evidence that it decreased significantly in the early stages of the COVID-19 pandemic, between March 2020 and May 2020 [14]. The Eurofound report does not discuss Switzerland; however, other studies suggest that there has been an increase in emotional distress in Swiss young adults [15] and that undergraduate students have experienced higher levels of stress, depression, anxiety, and loneliness compared to the time before the COVID-19 outbreak [10]. Furthermore, another study projects that the average Swiss person would suffer a loss of 0.205 years of life due to the psychosocial consequences of COVID-19 confinement measures [16].

The data from Eurofound [8] also suggest that European employees have experienced a dramatic increase in WFH. About $37 \%$ of the EU working population transitioned to WFH as a result of the pandemic, and $24 \%$ WFH for the first time. Before the pandemic, employees had considered remote working a benefit when it followed their preferences. However, the COVID-19 lockdown changed this by forcing many employees into mandatory WFH [2]. This posed various challenges for employees without prior WFH experience, such as organizing the workspace, establishing new communication channels with colleagues, coping with work isolation, or managing boundaries between work and non-work [17-19]. Without proper support from the employer or insufficient resources to manage these challenges, mandatory WFH may become a burden that negatively affects employees' well-being [4] and, in turn, their performance [17]. Furthermore, the increase in WFH has been highlighted as a potential threat to parents with small children at home, as this group is likely to experience difficulties in combining work duties with home schooling and household chores $[8,18]$.

Indisputably, the COVID-19 pandemic has had a strong impact on many aspects of our lives and will continue to do so for months and years to come. However, the consequences of the crisis and societal reactions to the challenges posed by the virus are not deemed solely negative. The new situation also holds opportunities for positive shifts in our work and private lives that were impossible before the COVID-19 crisis. Many may see this crisis as an opportunity to learn how to cope with profound changes in everyday life and even to adopt new proactive behaviors. For instance, some employees may discover that the new ways of working (e.g., WFH) facilitate more productivity and are more satisfying compared to working in an office [20]. Data collected from employees in Denmark and Germany between March and May 2020 [21] suggest that 71\% of respondents felt informed and well prepared for the changing work situation and WFH. Participants also reported several advantages of working from home, such as perceived control over the workday, working more efficiently, or saving time previously spent commuting. In contrast, some reported disadvantages of WFH included social isolation, loss of the value of work, and a lack of important work equipment. Nonetheless, respondents reported overall relatively more positive experiences of WFH than negative ones. Thus, we argue that more balanced studies are needed that examine both the negative and positive impact of the COVID-19 crisis on peoples' lives, health, and well-being, considering differential effects in diverse subgroups. Such studies have the potential to conclude how to diminish the 
negative and enhance the positive outcomes of the current and future pandemic-related crises in the working population.

\section{Aim and objectives}

The overall aim of the present study was to examine the actual and perceived overall impact of the COVID-19 crisis on employees' work and private life, along with its consequences for mental well-being (MWB) and selfrated health $(\mathrm{SRH})$ in the German and Swiss working populations. Specifically, we pursued the following objectives:

1. To investigate the perceived positive and negative impact of the COVID-19 crisis on work and private life as well as to assess actual changes in work and private life routines induced by the crisis.

2. To examine which sociodemographic variables and which actual changes in work and private life routines are associated with perceived positive and negative impact of the COVID-19 crisis on work and private life.

3. To investigate how the actual changes and perceived overall impact of the COVID-19 crisis on work and private life are associated with MWB and SRH as relevant health outcomes.

Although SRH has been identified as a relevant predictor of mental distress during the COVID-19 pandemic [6, 22], to our knowledge, it has not been studied as an outcome variable in combination with MWB indicators as in our study.

\section{Methods}

Data were collected from employees in Germany and Switzerland through an online panel service in April 2020, when both countries were in full lockdown as part of the control measures relating to COVID-19. Participants received a small monetary incentive for completing the survey. Participation was voluntary and participant anonymity and confidentiality of their data were assured and emphasized. We excluded participants who indicated that they worked less than 20 hours per week, who were self-employed, or who were not within the age range of 18 to 65 years.

\section{Sample}

The total sample included 2,216 persons, 98 of whom with missing data were removed from the analysis, resulting in a final sample of 2,118 participants. The mean age of the sample was 46.51 years $(S D=11.28)$. Table 1 shows additional characteristics of the sample: $55 \%$ were male, $77 \%$ were from Germany, and $72 \%$ were living with a partner, family, or in a shared housing.

Table 1 Sociodemographic characteristics of the sample 


\begin{tabular}{|c|c|c|}
\hline & $N$ & (\%) \\
\hline \multicolumn{3}{|l|}{ Gender } \\
\hline Male & 1,160 & 55 \\
\hline Female & 958 & 45 \\
\hline \multicolumn{3}{|l|}{ Country } \\
\hline Germany & 1,629 & 77 \\
\hline Switzerland & 489 & 23 \\
\hline \multicolumn{3}{|l|}{ Age } \\
\hline $18-30$ & 208 & 10 \\
\hline $31-40$ & 481 & 23 \\
\hline $41-50$ & 533 & 25 \\
\hline $51-60$ & 675 & 32 \\
\hline $61-65$ & 221 & 10 \\
\hline \multicolumn{3}{|l|}{ Living situation } \\
\hline Alone & 587 & 28 \\
\hline Family/partner/shared & 1,531 & 72 \\
\hline
\end{tabular}

Note: $N=2,118$

\section{Measures}

\section{Perceived overall impact of COVID-19 on work and private life.}

Assuming that both improvements and deteriorations can simultaneously occur due to COVID-19, we designed four separate items (see the supplementary file "Survey_en.pdf") to assess participants' subjective evaluation of the overall impact of the COVID-19 crisis on their work and private lives: "The Corona-crisis has (a) worsened my work life; (b) improved my work life; (c) worsened my private life; (d) improved my private life." The response scale ranged from $1=$ strongly disagree to $5=$ strongly agree. As a primer to this question, we defined the Coronacrisis as follows:

"The following questions deal directly with the current COVID-19 (Corona) pandemic and the consequent regulations from the government (i.e., business closures, school closures, event bans, contact reduction in public spaces, etc.). Hereafter, we refer to this collectively as the Corona-crisis. Please compare your current situation with the situation as it was before the government regulations."

\section{Changes in work and private life routines.}

The following items examined qualitative and quantitative changes in participants' work and private life routines resulting from the COVID-19 crisis: (a) change in employment contract (no change; short-time work[1] with a 
reduced contract, short-time work with a contract reduced to 0 hours, job loss); (b) proportion of WFH before and after COVID-19 (0\% to $100 \%$; participants were grouped into three categories according to their answers: None, Experienced, New[2]); (c) changes in quantity of working time;; (d) changes in quantity of leisure time; and (e) changes in quantity of caring duties. The response scale for items $\mathrm{c}, \mathrm{d}$, and e ranged from $1=$ strongly decreased to 5 = strongly increased. For the statistical analysis, responses were grouped into three categories: decreased $(1+2)$, unchanged (3), increased (4+5).

\section{Mental well-being.}

MWB was assessed with the Warwick-Edinburgh Mental Well-Being Scale (WEMWBS) [23]. Specifically, we used the German translation of the 7-item short version of the WEMWBS [24]. WEMWBS is a measure of MWB capturing the positive aspects of mental health, namely, positive affect (feelings of optimism, relaxation), satisfying interpersonal relationships, and positive functioning (clear thinking, self-acceptance, competence, autonomy). The response scale ranged from $1=$ never to $5=$ all the time. For the statistical analysis (i.e., ordinal logistic regression model), we grouped participants into six categories according to their overall score in percentiles $(10 \%, 25 \%, 50 \%, 75 \%, 90 \%, 99 \%)$.

\section{Self-rated health.}

SRH was assessed with a single item: "In general, how would you evaluate your health?" [25]. The response scale ranged from 1 = very bad to 5 = very good. The application of single-item measures for self-evaluated health is a gold standard in public health research [26].

\section{Statistical analysis}

Data analysis was carried out using $\mathrm{R}$ version 4.0.2. In the first step, four ordinal logistic regression models using polr from the MASSR package [27] were fitted to assess associations of the perceived overall impact of COVID-19 on work and private life as outcome variables with sociodemographic factors (gender, age, country, living situation) and factors related to changes in work and private life routines (changes in employment contract, WFH, work time, leisure time, caring duties) as independent variables. To verify that there was no multicollinearity, the variables were tested a priori using the variance inflation factor tested vif from the car R package [28] (VIF <2). The results are presented as adjusted odds ratio (OR) with $95 \%$ confidence intervals $(95 \% \mathrm{Cl})$ interpreted as the OR of reporting a higher level of the impact compared to the reference category.

Further, two additional ordinal logistic regression models were fitted to investigate the association between the perceived overall impact of COVID-19 on work and private life[3] and actual changes in work and private life routines as independent variables and MWB with SRH as outcome variables. In both models, we also controlled for possible confounders (gender, age, country, living situation). The results are presented as adjusted OR with $95 \% \mathrm{Cl}$ interpreted as the OR of reporting a higher level of MWB/SRH compared to the reference category.

\section{Footnote:}

[1] Short-time work is defined as "public programs that allow firms experiencing economic difficulties to temporarily reduce the hours worked while providing their employees with income support from the State for the hours not worked" (European Commission, 2020, Retrieved from: https://eur-lex.europa.eu/legalcontent/EN/TXT/?qid=1587138033761\&uri=CELEX\%3A52020PC0139). 
[2] "None" = 0\% WFH before COVID-19, 0\% after; "Experienced" = at least 10\% WFH before and at least 10\% after COVID-19; "New" = 0\% WFH before and at least 10\% after COVID-19.

[3] Participants were grouped into three categories according to their answers: disagree (1+2), neither/nor (3), agree $(4+5)$.

\section{Results}

\section{Perceived overall impact of COVID-19 crisis and changes in work and private life routines}

Table 2 shows the results for the four items related to the perceived overall impact of the COVID-19 crisis on work and private life. Thirty percent of participants (strongly) agreed that their work life had worsened $(M=2.72, S D=$ 1.37 ) and $31 \%$ (strongly) agreed that their private life had worsened $(M=2.65, S D=1.35)$ as a result of the COVID19 crisis. In contrast, $11 \%$ (strongly) agreed that their work life had improved $(M=1.9, S D=1.10)$ and $14 \%$ (strongly) agreed that their private life had improved $(M=2.02, S D=1.16)$ as a result of the COVID-19 crisis.

Table 2

Overview of perceived impact on work and private life

\begin{tabular}{|lllll|}
\hline & Work life & & Private life \\
\hline & Worsened & Improved & Worsened & Improved \\
\hline$N(\%)$ & $N(\%)$ & $N(\%)$ & $N(\%)$ \\
\hline Strongly disagree & $593(28)$ & $1,059(50)$ & $625(29)$ & $998(47)$ \\
\hline Disagree & $352(17)$ & $469(22)$ & $355(17)$ & $432(20)$ \\
\hline Neither agree nor disagree & $524(25)$ & $368(17)$ & $494(23)$ & $407(19)$ \\
\hline Agree & $405(19)$ & $163(8)$ & $442(21)$ & $222(11)$ \\
\hline Strongly agree & $244(11)$ & $59(3)$ & $202(10)$ & $59(3)$ \\
\hline Note: $N=2,118$ & & & & \\
\hline
\end{tabular}

Table 3 reports actual changes in work and private routines. Seventy-two percent of participants did not experience a change in their employment contract, while $27 \%$ were affected by mandatory short-time work, and $1 \%$ lost their job as a result of the COVID-19 crisis. Fifty-one percent reported to WFH and of those, 20\% reported doing so for the first time. The quantity of work time remained unchanged for $51 \%$ of participants, whereas it decreased for $38 \%$ and increased for $11 \%$. The quantity of leisure time remained unchanged for $42 \%$, whereas $36 \%$ reported an increase and $22 \%$ a decrease. Finally, $75 \%$ reported no change in the quantity of caring duties, while caring duties increased for $18 \%$ and decreased for $7 \%$. 
Table 3

Changes in work and private life routines

\begin{tabular}{|c|c|c|}
\hline & $N$ & (\%) \\
\hline \multicolumn{3}{|l|}{ Working contract } \\
\hline No change & 1,528 & 72 \\
\hline Short-time ${ }^{a}$ & 382 & 18 \\
\hline Short-time $(0)^{b}$ & 183 & 9 \\
\hline Job loss & 25 & 1 \\
\hline \multicolumn{3}{|l|}{ Work from home (WFH) } \\
\hline None & 1,026 & 48 \\
\hline Experienced & 661 & 31 \\
\hline New & 431 & 20 \\
\hline \multicolumn{3}{|l|}{ Working time } \\
\hline Decreased & 804 & 38 \\
\hline Unchanged & 1,090 & 51 \\
\hline Increased & 224 & 11 \\
\hline \multicolumn{3}{|l|}{ Leisure time } \\
\hline Decreased & 473 & 22 \\
\hline Unchanged & 878 & 42 \\
\hline Increased & 767 & 36 \\
\hline \multicolumn{3}{|l|}{ Caring duties } \\
\hline Decreased & 140 & 7 \\
\hline Unchanged & 1,584 & 75 \\
\hline Increased & 394 & 18 \\
\hline \multicolumn{3}{|c|}{${ }^{a}$ Work hours temporarily partly reduced by employe } \\
\hline
\end{tabular}

\section{Factors associated with perceived impact on work life}

Table 4 shows OR comparisons between different subgroups concerning their evaluation of the degree to which their work life had worsened or improved due to the COVID-19 crisis, assessed by two separate dependent variables. Regarding perceived negative impact on work life, change in employment contract demonstrated the highest OR of reporting a deterioration of work life. The association was particularly strong in participants who had their contract reduced to mandatory short-time work with 0 working hours (OR $=9.72 ; 95 \% \mathrm{Cl}$ : 6.85-13.86) 
and in those who had lost their job (OR $=35.07 ; 95 \% \mathrm{Cl}$ : 14.89-90.03). Further, participants who reported a change in their work time had a significantly higher OR of reporting a deterioration of work life. This association was stronger for those whose work time had decreased (OR $=2.95 ; 95 \% \mathrm{Cl}$ : 2.33-3.74) compared to those with increased work time $(\mathrm{OR}=2.06, \mathrm{Cl}$ : $1.55-2.73)$. Finally, changes in leisure time and increased caring duties were significantly associated with perceived deterioration of work life. This association was particularly strong for a decrease in leisure time $(\mathrm{OR}=1.62 ; 95 \% \mathrm{Cl}$ : $1.29-2.03)$ and an increase in caring duties $(\mathrm{OR}=1.58 ; 95 \% \mathrm{Cl}$ : $1.27-$ 1.97).

Regarding perceived positive impact of COVID-19 on work life, WFH achieved the highest OR of reporting an improvement in work life. The association was particularly strong in those who had started to WFH for the first time (OR $=2.77 ; 95 \% \mathrm{Cl}$ : 2.22-3.45). Further, older employees in the 51-60 and 61-65 age groups had significantly lower odds of reporting a positive impact of COVID-19 on work life (OR = 0.71; 95\% Cl: 0.52-0.95; OR $=0.61 ; 95 \% \mathrm{Cl}: 0.43-0.84)$ as well as short-time employees, in particular those with a contract reduced to 0 working hours $(\mathrm{OR}=0.53 ; 95 \% \mathrm{Cl}: 0.37-0.77)$, and those who reported a decrease in work time $(\mathrm{OR}=0.61 ; 95 \% \mathrm{Cl}$ : 0.48-0.78). Finally, increase in leisure time was significantly associated with a positive impact on work life (OR = $1.91 ; 95 \% \mathrm{Cl}: 1.54-2.38)$. 
Table 4

Associations between sociodemographic factors, changes in routines, and positive/negative impact on work/private life

\begin{tabular}{ccllllll} 
Work life worsened & \multicolumn{2}{l}{$\begin{array}{l}\text { Work life } \\
\text { improved }\end{array}$} & \multicolumn{2}{l}{$\begin{array}{l}\text { Private life } \\
\text { worsened }\end{array}$} & \multicolumn{2}{c}{ Private life improved } \\
\hline OR & $95 \% \mathrm{Cl}$ & OR & $\begin{array}{l}95 \% \\
\mathrm{Cl}\end{array}$ & OR & $\begin{array}{l}95 \% \\
\mathrm{Cl}\end{array}$ & OR & $95 \% \mathrm{Cl}$ \\
\hline
\end{tabular}

Gender

Female (Ref.)

\begin{tabular}{|c|c|c|c|c|c|}
\hline Male & 0.91 & $\begin{array}{l}0.78- \\
1.07\end{array}$ & 0.93 & $\begin{array}{l}0.78- \\
1.09\end{array}$ & 1.05 \\
\hline
\end{tabular}

Nationality

Germany (Ref.)

Switzerland

0.87

$0.72-$

1.15

$0.95-\quad 0.86$

$0.71-\quad 1.13$

$0.93-$

1.05

1.4

1.03

1.37

Age

18-30 (Ref.)

$\begin{array}{lllllllll}31-40 & 0.93 & 0.69- & 1.04 & 0.76- & 0.76 & 0.56- & 0.93 & 0.69- \\ & & 1.26 & & 1.41 & & 1.02 & & 1.27\end{array}$

41-50

1.08

$0.8-\quad 0.96$

$0.71-\quad 0.77$

0.57- 0.88

0.65-1.2

$51-60$

1.23

0.92-

0.71 *

$0.52-$

0.76

1.03

1.64

0.95

$0.57-\quad 0.8$

0.59

$61-65$

$1.55^{\star}$

$1.09-$

2.2

0.51 **

$0.35-$

0.74

0.58 **

1

1.07

Living situation

Alone (Ref.)

Fam./part./shared

0.89

$0.74-\quad 1.08$

$0.9-$

$0.41^{\star \star \star}$

0.34

$0.41-$
0.82

0.77

$0.53-1.1$

Change in contract

No change (Ref.)

Short-time ${ }^{a}$

$3.45^{\star \star \star}$

$\begin{array}{ll}2.66- & 0.68 * \star \\ 4.47\end{array}$

$0.52-$
0.89

1.22

$0.95-1.32$ *

$1.01-$

$0.49 \quad 2.11$

Note: $N=2,118$

* $p<0.05$, ** $p<0.01$, *** $p<0.001$

a Work hours partly reduced

${ }^{b}$ Work hours reduced to 0 


\begin{tabular}{|c|c|c|c|c|c|c|c|c|}
\hline \multirow[b]{2}{*}{ Short-time $(0)^{\mathrm{b}}$} & \multicolumn{2}{|c|}{ Work life worsened } & \multicolumn{2}{|c|}{$\begin{array}{l}\text { Work life } \\
\text { improved }\end{array}$} & \multicolumn{2}{|c|}{$\begin{array}{l}\text { Private life } \\
\text { worsened }\end{array}$} & \multicolumn{2}{|c|}{ Private life improved } \\
\hline & $9.72^{\star \star \star}$ & $\begin{array}{l}6.85- \\
13.86\end{array}$ & $0.53^{\star \star \star}$ & $\begin{array}{l}0.37- \\
0.77\end{array}$ & 1.06 & $\begin{array}{l}0.78- \\
1.45\end{array}$ & $1.57 \star \star$ & $\begin{array}{l}1.13- \\
2.18\end{array}$ \\
\hline Job loss & $35.07 * \star \star$ & $\begin{array}{l}14.89- \\
90.03\end{array}$ & $0.4^{\star}$ & $\begin{array}{l}0.16- \\
0.92\end{array}$ & 1.21 & $\begin{array}{l}0.6- \\
2.44\end{array}$ & 1.67 & $0.77 v 3.56$ \\
\hline \multicolumn{9}{|l|}{ Home office } \\
\hline \multicolumn{9}{|l|}{ None (Ref.) } \\
\hline Experienced & 1.18 & $\begin{array}{l}0.98- \\
1.41\end{array}$ & 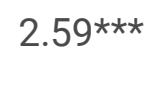 & $\begin{array}{l}2.14- \\
3.14\end{array}$ & 1.02 & $\begin{array}{l}0.85- \\
1.22\end{array}$ & $1.72^{\star \star \star}$ & $\begin{array}{l}1.43- \\
2.08\end{array}$ \\
\hline New & 1.21 & $\begin{array}{l}0.98- \\
1.5\end{array}$ & $2.77^{\star \star \star}$ & $\begin{array}{l}2.22- \\
3.45\end{array}$ & 1.07 & $\begin{array}{l}0.87- \\
1.32\end{array}$ & $1.41^{\star \star}$ & $\begin{array}{l}1.14- \\
1.76\end{array}$ \\
\hline \multicolumn{9}{|l|}{ Working time } \\
\hline \multicolumn{9}{|c|}{ Unchanged (Ref.) } \\
\hline Decreased & $2.95^{\star \star \star}$ & $\begin{array}{l}2.33- \\
3.74\end{array}$ & $0.61^{\star \star \star}$ & $\begin{array}{l}0.48- \\
0.78\end{array}$ & 0.9 & $\begin{array}{l}0.72- \\
1.14\end{array}$ & 0.89 & $0.7-1.13$ \\
\hline Increased & $2.06^{\star \star \star}$ & $\begin{array}{l}1.55- \\
2.73\end{array}$ & 1.32 & $\begin{array}{l}0.99- \\
1.75\end{array}$ & 1.13 & $\begin{array}{l}0.86- \\
1.49\end{array}$ & 1.08 & $\begin{array}{l}0.81- \\
1.44\end{array}$ \\
\hline \multicolumn{9}{|l|}{ Leisure time } \\
\hline \multicolumn{9}{|c|}{ Unchanged (Ref.) } \\
\hline Decreased & $1.62^{\star \star \star}$ & $\begin{array}{l}1.29- \\
2.03\end{array}$ & 0.96 & $\begin{array}{l}0.75- \\
1.21\end{array}$ & $2.62^{\star \star \star}$ & $\begin{array}{l}2.09- \\
3.28\end{array}$ & 0.85 & $\begin{array}{l}0.67- \\
1.08\end{array}$ \\
\hline Increased & $1.27^{\star}$ & $\begin{array}{l}1.04- \\
1.56\end{array}$ & $1.91^{\star \star \star}$ & $\begin{array}{l}1.54- \\
2.38\end{array}$ & $1.3^{*}$ & $\begin{array}{l}1.06- \\
1.59\end{array}$ & $2.25^{\star \star \star}$ & $\begin{array}{l}1.82- \\
2.79\end{array}$ \\
\hline \multicolumn{9}{|l|}{ Caring duties } \\
\hline \multicolumn{9}{|c|}{ Unchanged (Ref.) } \\
\hline Decreased & 1.13 & $\begin{array}{l}0.8- \\
1.57\end{array}$ & 1.11 & $\begin{array}{l}0.78- \\
1.57\end{array}$ & $1.62^{\star \star}$ & $\begin{array}{l}1.19- \\
2.22\end{array}$ & 1.35 & $\begin{array}{l}0.96- \\
1.89\end{array}$ \\
\hline Increased & $1.58^{\star \star \star}$ & $\begin{array}{l}1.27- \\
1.97\end{array}$ & 0.96 & $\begin{array}{l}0.77- \\
1.21\end{array}$ & $1.39 \star \star$ & $\begin{array}{l}1.12- \\
1.72\end{array}$ & $1.33^{\star}$ & $\begin{array}{l}1.07- \\
1.67\end{array}$ \\
\hline \multicolumn{9}{|l|}{ Note: $N=2,118$} \\
\hline \multicolumn{9}{|c|}{${ }^{\star} p<0.05, * * p<0.01, * \star * p<0.001$} \\
\hline \multicolumn{9}{|c|}{ a Work hours partly reduced } \\
\hline${ }^{\mathrm{b}}$ Work hours reduce & & & & & & & & \\
\hline
\end{tabular}

Factors associated with perceived impact on private life 
Table 4 also shows OR comparisons within different subgroups concerning their evaluation of the degree to which their private life had worsened or improved due to the COVID-19 crisis, assessed by two separate dependent variables. Regarding perceived negative impact on private life, the subgroup of participants living with a partner, family, or in a shared housing had significantly lower odds of reporting the deterioration of their private life compared to those living alone $(\mathrm{OR}=0.41 ; 95 \% \mathrm{Cl}: 0.34-0.49)$. Further, the odds of reporting deterioration of private life were lower for the $61-65$ age group ( $\mathrm{OR}=0.58 ; 95 \% \mathrm{Cl}: 0.41-0.82)$. Finally, changes in the quantity of leisure time and quantity of caring duties were associated with perceived deterioration of private life, and this association was particularly strong for a decrease in leisure time (OR $=2.62 ; 95 \% \mathrm{Cl}$ : 2.09-3.28) and decrease in caring duties $(\mathrm{OR}=1.62 ; 95 \% \mathrm{Cl}: 1.19-2.22)$.

Regarding perceived positive impact on private life, the strongest association was with an increase in leisure time $(\mathrm{OR}=2.25 ; 95 \% \mathrm{Cl}: 1.82-2.79)$, followed by living with a partner, family, or in a shared housing $(\mathrm{OR}=1.74,95 \% \mathrm{Cl}$ : 1.44-2.11); WFH, particularly among those with prior WFH experience (OR $=1.72 ; 95 \% \mathrm{Cl}: 1.43-2.08)$; and an increase in caring duties $(\mathrm{OR}=1.33 ; 95 \% \mathrm{Cl}$ : 1.07-1.67). Finally, short-time workers had significantly higher odds

of reporting a positive impact on their private life compared to workers without any change, especially those with a contract reduced to 0 working hours (OR $=1.57 ; 95 \% \mathrm{Cl}: 1.13-2.18)$.

\section{Perceived and actual impact of COVID-19 and the associations with mental well-being and self-rated health}

Table 5 shows the results of the associations between perceived overall impact, the actual changes in work and private life routines, and relevant health outcomes in terms of MWB and $\mathrm{SRH}$, controlled for various sociodemographic variables. Regarding the perceived overall impact, participants who (strongly) agreed that COVID-19 had worsened their work life reported significantly lower MWB (OR $=0.61 ; 95 \%$ Cl: 0.49-0.76) compared to those who (strongly) disagreed. In addition, participants who neither agreed nor disagreed that their work life had worsened reported lower MWB (OR $=0.71 ; 95 \% \mathrm{Cl}$ : $0.58-0.88)$ compared to those who (strongly) disagreed. A strong negative association could also be seen regarding perceived negative impact on private life: participants who (strongly) agreed that their private life had worsened reported lower $\mathrm{MWB}(\mathrm{OR}=0.62 ; 95 \% \mathrm{Cl}$ : $0.51-0.75)$ and $\mathrm{SRH}$ scores (OR $=0.67 ; 95 \% \mathrm{Cl}$ : 0.54-0.83) compared to those who (strongly) disagreed. Both outcomes were also negatively associated with employees who neither agreed nor disagreed that their private life had worsened $(\mathrm{OR}=0.80 ; 95 \% \mathrm{Cl}: 0.65-0.99 ; \mathrm{OR}=0.66 ; 95 \% \mathrm{Cl}: 0.53-0.83)$ compared to those who (strongly) disagreed. Finally, participants who (strongly) agreed that their private life had improved as a result of the COVID19 crisis had higher odds of reporting a higher MWB score (OR $=1.39 ; 95 \% \mathrm{Cl}$ : $1.08-1.80)$ compared to those who (strongly) disagreed.

Regarding the impact of actual changes in work and private life routines on MWB and SRH, mandatory short-time workers with a contract reduced to 0 working hours reported significantly lower MWB (OR $=0.57 ; 95 \%$ Cl: 0.41$0.79)$ and $\mathrm{SRH}(\mathrm{OR}=0.49 ; 95 \% \mathrm{Cl}: 0.35-0.70)$ compared to participants without any change in their employment contract. In contrast, an increase in leisure time was positively associated with both better MWB $(O R=1.23 ; 95 \%$ Cl: $1.01-1.51)$ and SRH (OR $=1.45 ; 95 \% \mathrm{Cl}: 1.16-1.82)$. 
Table 5

Associations between perceived impact on work/private life, actual changes in routines, MWB, and SRH

\begin{tabular}{|c|c|c|c|c|}
\hline & \multicolumn{2}{|c|}{ Mental well-being } & \multicolumn{2}{|c|}{ Self-rated health } \\
\hline & OR & $95 \% \mathrm{Cl}$ & OR & $95 \% \mathrm{Cl}$ \\
\hline \multicolumn{5}{|l|}{ Work life worsened } \\
\hline \multicolumn{5}{|l|}{ Disagree (Ref.) } \\
\hline Neither/nor & 0.71 ** & $0.58-0.88$ & 0.91 & $0.73-1.14$ \\
\hline Agree & $0.61 * * *$ & $0.49-0.76$ & $0.76^{*}$ & $0.60-0.97$ \\
\hline \multicolumn{5}{|l|}{ Work life improved } \\
\hline \multicolumn{5}{|l|}{ Disagree (Ref.) } \\
\hline Neither/nor & 0.89 & $0.71-1.12$ & 0.84 & $0.66-1.08$ \\
\hline Agree & 1.07 & $0.82-1.41$ & 0.94 & $0.70-1.26$ \\
\hline \multicolumn{5}{|l|}{ Private life worsened } \\
\hline \multicolumn{5}{|l|}{ Disagree (Ref.) } \\
\hline Neither/nor & $0.80 *$ & $0.65-0.99$ & $0.66^{\star \star \star}$ & $0.53-0.83$ \\
\hline Agree & $0.62^{\star \star \star}$ & $0.51-0.75$ & $0.67 * \star \star$ & $0.54-0.83$ \\
\hline \multicolumn{5}{|l|}{ Private life improved } \\
\hline \multicolumn{5}{|l|}{ Disagree (Ref.) } \\
\hline Neither/nor & 1.03 & $0.83-1.28$ & 1.04 & $0.83-1.32$ \\
\hline Agree & $1.39 * \star$ & $1.08-1.80$ & 1.1 & $0.83-1.46$ \\
\hline \multicolumn{5}{|l|}{ Change in contract } \\
\hline \multicolumn{5}{|l|}{ No change (Ref.) } \\
\hline Short-time (red.) & 0.95 & $0.73-1.24$ & 0.9 & $0.68-1.19$ \\
\hline Short-time (0) & $0.57 * \star \star$ & $0.41-0.79$ & $0.49 * * *$ & $0.35-0.70$ \\
\hline Job loss & 0.71 & $0.34-1.47$ & 0.79 & $0.35-1.81$ \\
\hline \multicolumn{5}{|l|}{ Home-office } \\
\hline \multicolumn{5}{|l|}{ None (Ref.) } \\
\hline Experienced & 1.05 & $0.88-1.26$ & 0.99 & $0.81-1.20$ \\
\hline New & 1.14 & $0.92-1.40$ & 1.07 & $0.85-1.33$ \\
\hline
\end{tabular}

Note: $N=2,118$

* $p<0.05$, ** $p<0.01$, *** $p<0.001$ 


\begin{tabular}{|c|c|c|c|c|}
\hline & \multicolumn{2}{|c|}{ Mental well-being } & \multicolumn{2}{|c|}{ Self-rated health } \\
\hline \multicolumn{5}{|l|}{ Working time } \\
\hline \multicolumn{5}{|c|}{ Unchanged (Ref.) } \\
\hline Decreased & 1.14 & $0.90-1.44$ & 1.02 & $0.79-1.32$ \\
\hline Increased & 1.2 & $0.91-1.59$ & 1.17 & $0.87-1.58$ \\
\hline \multicolumn{5}{|l|}{ Leisure time } \\
\hline \multicolumn{5}{|c|}{ Unchanged (Ref.) } \\
\hline Decreased & 0.81 & $0.64-1.02$ & 0.92 & $0.72-1.18$ \\
\hline Increased & $1.23^{*}$ & $1.01-1.51$ & $1.45^{\star \star}$ & $1.16-1.82$ \\
\hline \multicolumn{5}{|l|}{ Caring duties } \\
\hline \multicolumn{5}{|c|}{ Unchanged (Ref.) } \\
\hline Decreased & 1.06 & $0.77-1.47$ & 0.82 & $0.58-1.17$ \\
\hline Increased & 1 & $0.80-1.24$ & 1.06 & $0.84-1.33$ \\
\hline \multicolumn{5}{|l|}{ Note: $N=2,118$} \\
\hline \multicolumn{5}{|c|}{${ }^{\star} p<0.05, * \star p<0.01, * \star * p<0.001$} \\
\hline
\end{tabular}

Controlled for gender, age, country, and living situation

\section{Discussion}

The present study aimed to examine the actual and perceived overall impact of the COVID-19 crisis on employees' work and private life along with the consequences for MWB and general SRH in the German and Swiss working populations. The first objective of the study was to assess the perceived positive and negative impact of the COVID-19 crisis on work and private life in Germany and Switzerland as well as related actual changes in work and private life routines. Although the research has thus far mostly emphasized the negative impact of the COVID-19 crisis on the working population [29], our data show that more than $40 \%$ of participants perceived no negative changes and over $10 \%$ even positive shifts in both work and private life. This can be partly explained by looking at the proportion of employees that experienced changes in their daily routines. Regarding the changes in work life routines, overall, $28 \%$ of participants were affected by a change in their employment contract and $49 \%$ by changes in the quantity of work time. This result is almost identical to the findings for the German sample in the Eurofound report [8]. Regarding private life, quantity of leisure time changed for $58 \%$ and quantity of caring duties for $25 \%$. Finally, about half the participants in our sample reported to WFH at least part of their work time, and $20 \%$ of those did so for the first time. This finding is also in line with Eurofound's data [8] showing that $24 \%$ of participants reported WFH for the first time. Overall, the proportion of people affected by changes in work and private life is comparable but hardly exceeds $50 \%$.

Looking at the second objective relating to the factors associated with perceived impact on work and private life, a temporary reduction in contracted work hours (i.e., mandatory short-time work) and changes in work time were 
strongly associated with reporting deterioration of work life. This is in line with previous research suggesting that employees whose contract had been reduced or terminated due to the lockdown measures were particularly vulnerable to developing mental health problems [7, 9]. For those affected by short-time work, fear of losing their job significantly contributed to the distress and negatively affected MWB [3]. As one would expect, the few who lost their jobs were most negatively affected by the crisis. Further, an increase in caring duties and, perhaps more surprisingly, changes in leisure time were associated with perceived deterioration of work life. Changes in private life routines, such as amount of leisure time, may require efforts for readjustments that can also interfere with work life. Finally, older employees in the 61-65 age group had a higher OR of reporting deterioration of their work life. An explanation can be that older workers may be more sensitive to changes in daily structure and less flexible in adapting to a new situation, such as mandatory WFH, reduced live contact with colleagues, and the use of remote work technology.

In contrast, the COVID-19 measures also seem to have related to some positive shifts in work life. WFH was most strongly associated with perceived positive impact of the COVID-19 crisis on work life. Interestingly, the group that reported WFH for the first time had the highest odds of experiencing a positive shift in their work life as a result of the COVID-19 lockdown, supporting evidence from Ipsen and colleagues [21]. This positive impact of WFH might be explained by various benefits, such as a reduction or absence of commute time, more job autonomy, more opportunities to try out new things, and general increased flexibility in the organization of the workday. Further, a decrease in work time was negatively associated with perceived positive impact on work life. Indeed, a reduction in work time may not only cause financial problems but may also reduce important daily routines and social contact at work, thus impeding perceived improvement of work life. In contrast, an increase in leisure time was associated with perceived positive impact of the COVID-19 crisis on work life. From the resource perspective, more time for leisure may allow for better recovery from work and rebuilding of personal resources [30, 31], which can then help an individual deal with work demands. Finally, the oldest age groups, 54-60 and 61-65 years, were less likely to report an improvement in their work life. As in the case of deterioration of work life, older employees may struggle more with the new situation and may be less successful in transforming the new situation to their benefit.

Regarding the perceived impact on private life, participants living alone showed significantly higher odds of reporting a deterioration of their private life compared to those living with a partner, family, or in a shared housing. The COVID-19 lockdown substantially restricted possibilities for social interactions beyond one's own household, particularly affecting people living alone. Individuals who live alone and have restricted social contact over a longer period may experience high levels of loneliness [8]. This, in turn, threatens their MWB [32]. Interestingly, participants over 60 years old had a significantly lower OR of reporting the deterioration of their private life. Older employees may be more resilient to situational changes outside of their household as a result of having wellestablished private life routines that help them cope with adverse situations. As such, they might be less dependent on the number of social contacts beyond their household, and they may have developed more mature emotion regulation strategies than the younger generation, which allows them to better cope with difficulties in private life [33].

Perceived positive impact of the COVID-19 crisis on private life was strongly associated with an increase in leisure time, living with others, changes in employment contract, WFH, and an increase in caring duties. Increase in leisure time and changes in employment contract (i.e., mandatory short-time work) imply that employees can devote more time and attention to their private life. An increase in WFH reduces or eliminates commuting, which

Page $15 / 22$ 
is generally one of the most cited benefits of WFH [21]. WFH also allows for more interaction with family at home. Those experienced in WFH showed a stronger positive relationship than those who were new to WFH, probably as the latter had initially had to organize their workspace and set new routines, which imposed additional strain on them. The positive association with living with others shows the importance of having opportunities for direct exchange in such a crisis situation. This could also explain that an increase in caring duties, allowing for more exchange with family members, was associated with perceived positive shifts in private life.

Finally, our third objective was to investigate how perceived overall impact of the COVID-19 crisis on work and private life and actual changes induced by the lockdown measures were associated with MWB and SRH. Previous evidence has shown that these two health domains are not separate. Low SRH has been associated with increased odds of depression [22], displaying the relevance of SRH for psychologically demanding situations, such as the COVID-19 pandemic. Our results suggest a strong negative association between perceived negative impact on work and private life and MWB, and a positive association between perceived positive impact on private life and MWB. This indicates that the perceived negative impact of the crisis on both life domains has had severe consequences for MWB. In contrast, it seems that those who were able to cope with the COVID-19 crisis and translate the lockdown measures into some positive shifts in their private life, for instance, by engaging in new leisure activities or spending more time with family or friends, also benefited from the crisis in terms of increased MWB. Similar associations emerged between perceived impact and SRH, although the association with perceived negative impact on work life was less pronounced than in the case of MWB, and there was no significant association between perceived positive impact and $\mathrm{SRH}$. It seems that $\mathrm{SRH}$ was more affected by perceived changes in private life rather than in work life. It is interesting, however, that the perceived negative impact had such a strong association with $\mathrm{SRH}$, which is more stable over time than MWB.

Regarding the impact of actual changes, mandatory short-time work showed a strong negative association with both MWB and SRH. Mandatory short-time work leads to significant financial losses and, perhaps more importantly, to a loss of daily structure and routines, which seem to have detrimental effects on both MWB and $\mathrm{SRH}$. Conversely, an increase in leisure time was positively associated with MWB, and the link was even stronger with SRH. Plausibly, an increase in leisure time provides extra opportunities for individuals to engage in meaningful activities that provide them with important resources that benefit their MWB and SRH. Looking at the overall strength of the associations, it seems that MBW may be more affected by the perceived impact, as both are cognitive-emotional domains and are more dependent on the cognitive appraisal of one's situation and emotional experience. However, SRH may be more affected by actual changes in work and private life that increase or decrease opportunities to engage in activities that are perceived as beneficial to health.

\section{Limitations and strengths}

The contribution of this study should be considered in light of its research limitations. A major limitation is the cross-sectional design, which allowed us only to infer associations between variables but did not provide evidence of the directions of the associations or potential causality. Furthermore, the analyzed data stem from self-rating scales, and self-reported data may be influenced by common method biases [34], such as social desirability bias [35], particularly as COVID-19 is currently a dominant topic. Nevertheless, an online survey was the method of choice because it allowed for collecting a large amount of current data within a short period of time, which was a requirement to obtain valid data that accurately reflect the acute COVID-19 crisis situation. Further, we did not control for all variables that might have affected the results. For instance, coping with a crisis 
and MWB differ individually and may be influenced by variables such as personality traits, resilience, or coping style [36-39]. However, our study aimed to provide a broad picture of both the negative and positive impacts of the COVID-19 crisis on a large, diverse sample of the working population. Thus, it was beyond the scope of this study to investigate individual differences and characteristics. In addition, a more complete, lengthy survey would have reduced the participation rate.

Indeed, a strength of the present study is the relatively large sample size that allowed us to conduct a detailed analysis and explore different subgroups within the sample. Another strength is the time point of the data collection, as we launched the survey at the beginning of April 2020, close to the first peak of the COVID-19 outbreak in Germany and Switzerland, when the lockdown measures were initiated. This enabled us to capture a valid picture of the immediate impact of the lockdown measures. Moreover, the participants were asked about the present situation, which adds to the validity of the collected data compared to a retrospective survey design, in which participants must think back to the past. Finally, the combination of a subjective evaluation of the impact of the crisis with relevant, standardized public health indicators of MWB and SRH increases the relevance of the results to public health research and policymaking.

\section{Conclusion}

The present study contributes to our understanding of the impact of the COVID-19 crisis on work and private life. It provides evidence on the covariates of a more negative/positive perceived impact and on the associations with MWB and SRH in the German and Swiss working populations. Employees whose employment contract was affected by the crisis seem to have felt the greatest negative impact on their work life. This highlights the crucial role of (un-/under-)employment in a crisis, as employment is associated with several health-promoting factors that cannot be substituted in any other way [40]. Moreover, employees living alone represent a group whose private life seems to have been affected the most negatively due to physical distancing and the consequent social isolation. Thus, future interventions aimed at ameliorating the impact of lockdown measures should particularly address the situations of these groups.

Beyond the negative impact of the COVID-19 measures, we should also consider positive consequences that future interventions can foster. In particular, we found that an increase in WFH was associated with a positive shift in work life for many employees, and an increase in leisure time was associated with a positive shift in the private life domain. These findings hold relevant implications for policies regarding WFH at the organizational and legislative levels. Learning from the beneficial effects of WFH in a crisis can inform future organizational and legislative policies to support this form of working. As WFH had a stronger positive impact on private life in those who were experienced in this form of working, future WFH policies should include offering training and exchange of experience between employees on how to establish positive routines that are compatible with their private life. Further in-depth analyses of the impact of mandatory WFH will enhance our understanding of who benefits most from WFH. This will help employees to proactively identify their preferences and craft their work environment accordingly [41].

Many employees might have struggled to find sufficient time for combining work, leisure, and family before the COVID-19 crisis. Indeed, we saw that an increase in leisure time, for example, due to reduced or eliminated commuting time or reduced caring time, was particularly strongly related to a perceived improvement of the private life domain. More leisure time allows for dedicating extra time to activities one enjoys, and this may be

Page $17 / 22$ 
beneficial also for recovery and detachment from work [42] and mental health in general [43]. From a longitudinal research perspective, it would be interesting to further examine how the actual and perceived impact of the ongoing crisis changed over time and whether some of the new routines developed during the pandemic and the impact of the COVID-19 crisis on health outcomes will be maintained in the long term.

\section{List Of Abbreviations}

MWB $=$ Mental well-being

SRH = Self-rated health

WHO $=$ World Health Organization

PHEIC $=$ Public Health Emergency of International Concern

WFH $=$ Work from home

$\mathrm{EU}=$ European Union

$\mathrm{OR}=$ Odds ratio

$\mathrm{Cl}=$ Confidence interval

\section{Declarations}

\section{Ethics approval and consent to participate}

Informed consent was obtained from all participants, the study included adult participants (18+years) only. Participants voluntarily completed the questionnaires, guaranteeing their anonymity. For anonymous surveys on working/living conditions and self-reported mental well-being and health no ethical review was necessary under national, university, or departmental rules (Department of Data Protection at the University of Zurich, www.dsd.uzh.ch/en/). The study was conducted under strict observation of ethical and professional guidelines.

\section{Consent for publication}

Not applicable

\section{Availability of data and materials}

The datasets used and/or analysed during the current study are available from the corresponding author on reasonable request. The $\mathrm{R}$ code used for the statistical analysis is available in the GitHub repository: https://github.com/jesuismartin/covid

\section{Competing interests}

The authors declare that they have no competing interests.

\section{Funding}


MT received funding from the European Union's Horizon 2020 research and innovation programme under the Marie Skłodowska-Curie grant agreement No 801076, through the SSPH+ Global PhD Fellowship Programme in Public Health Sciences (GlobalP3HS) of the Swiss School of Public Health. RB, PK, and GB received funding from the University of Zurich Foundation. Beyond providing the funding, these funding bodies were not involved at any stage of the study.

\section{Authors' contributions}

MT planned and carried out data collection and analysis, interpretation of the results, writing and reviewing the manuscript in collaboration with the co-authors. RB contributed to the research concept, data collection, data analysis, and review of the manuscript. PK was involved with the conceptualization of the research, interpretation of the results, writing, and review of the manuscript. GB contributed to the conceptualization of the research, interpretation of results, writing, and review of the manuscript. All authors read and approved the final manuscript before submission.

\section{Acknowledgements}

The authors would like to thank to Roald Pijpker from Wageningen University for his helpful comments during the final editing of the manuscript.

\section{References}

1. World Health Organization. World Health Organization Director-General's statement on IHR Emergency Committee on Novel Coronavirus (2019-nCoV).

2. Kniffin KM, Narayanan J, Anseel F, Antonakis J, Ashford SP, Bakker A, et al. COVID-19 and the workplace: implications, issues, and insights for future research and action. Am Psychol. 2020; doi:10.1037/amp0000716.

3. Koh D, Goh HP. Occupational health responses to COVID-19: what lessons can we learn from SARS? J Occup Health. 2020;62:e12128; doi:10.1002/1348-9585.12128.

4. Brooks SK, Webster RK, Smith LE, Woodland L, Wessely S, Greenberg N, Rubin GJ. The psychological impact of quarantine and how to reduce it: rapid review of the evidence. The Lancet. 2020;395:912-920; doi:10.1016/S0140-6736(20)30460-8.

5. Rodríguez-Rey R, Garrido-Hernansaiz H, Collado S. Psychological impact and associated factors during the initial stage of the coronavirus (COVID-19) pandemic among the general population in Spain. Front Psychol. 2020;11:1540; doi:10.3389/fpsyg.2020.01540.

6. Wang C, Pan R, Wan X, Tan Y, Xu L, Ho CS, Ho RC. Immediate psychological responses and associated factors during the initial stage of the 2019 coronavirus disease (COVID-19) epidemic among the general population in China. Int J Environ Res Public Health. 2020; doi:10.3390/ijerph17051729.

7. Qiu J, Shen B, Zhao M, Wang Z, Xie B, Xu Y. A nationwide survey of psychological distress among Chinese people in the COVID-19 epidemic: implications and policy recommendations. Gen Psychiatr. 2020;33:e100213; doi:10.1136/gpsych-2020-100213.

8. Eurofound. Living, working and COVID-19: first findings - April 2020. 2020:1-11. 
9. Ozamiz-Etxebarria N, Idoiaga Mondragon N, Dosil Santamaría M, Picaza Gorrotxategi M. Psychological symptoms during the two stages of lockdown in response to the COVID-19 outbreak: an investigation in a sample of citizens in northern Spain. Front Psychol. 2020;11:1491; doi:10.3389/fpsyg.2020.01491.

10. Elmer T, Mepham K, Stadtfeld C. Students under lockdown: comparisons of students' social networks and mental health before and during the COVID-19 crisis in Switzerland. PLoS ONE. 2020;15:e0236337; doi:10.1371/journal.pone.0236337.

11. Carvalho Aguiar Melo M, Sousa Soares D de. Impact of social distancing on mental health during the COVID19 pandemic: an urgent discussion. Int J Soc Psychiatry. 2020;66:625-626; doi:10.1177/0020764020927047.

12. Venkatesh A, Edirappuli S. Social distancing in covid-19: what are the mental health implications? BMJ. 2020;369:m1379; doi:10.1136/bmj.m1379.

13. Pfefferbaum B, North CS. Mental health and the Covid-19 pandemic. N Engl J Med. 2020;383:510-512; doi:10.1056/NEJMp2008017.

14. Zacher $\mathrm{H}$, Rudolph $\mathrm{C}$. Individual differences and changes in subjective wellbeing during the early stages of the COVID-19 pandemic. Am Psychol. 2020; doi:10.1037/amp0000702.

15. Shanahan L, Steinhoff A, Bechtiger L, Murray AL, Nivette A, Hepp U, et al. Emotional distress in young adults during the COVID-19 pandemic: evidence of risk and resilience from a longitudinal cohort study. Psychol Med. 2020:1-10; doi:10.1017/S003329172000241X.

16. Moser DA, Glaus J, Frangou S, Schechter DS. Years of life lost due to the psychosocial consequences of COVID-19 mitigation strategies based on Swiss data. Eur Psychiatry. 2020;63:e58; doi:10.1192/j.eurpsy.2020.56.

17. Ozcelik H, Barsade SG. No employee an island: workplace loneliness and job performance. AMJ. 2018;61:2343-2366; doi:10.5465/amj.2015.1066.

18. Shimazu A, Nakata A, Nagata T, Arakawa Y, Kuroda S, Inamizu N, Yamamoto I. Psychosocial impact of COVID-19 for general workers. J Occup Health. 2020;62:e12132; doi:10.1002/1348-9585.12132.

19. Cho E. Examining boundaries to understand the impact of COVID-19 on vocational behaviors. J Vocat Behav. 2020:103437; doi:10.1016/j.jvb.2020.103437.

20. Kramer A, Kramer KZ. The potential impact of the Covid-19 pandemic on occupational status, work from home, and occupational mobility. J Vocat Behav. 2020:103442; doi:10.1016/j.jvb.2020.103442.

21. Ipsen C, Kirchner K, Hansen J. Experiences of working from home in times of COVID-19. International survey conducted the first months of the national lockdowns March-May, 2020.

https://www.forskningsdatabasen.dk/en/catalog/2595069795. Accessed 20 Aug 2020.

22. Gao J, Zheng P, Jia Y, Chen H, Mao Y, Chen S, et al. Mental health problems and social media exposure during COVID-19 outbreak. PLoS ONE. 2020;15:e0231924; doi:10.1371/journal.pone.0231924.

23. Tennant R, Hiller L, Fishwick R, Platt S, Joseph S, Weich S, et al. The Warwick-Edinburgh Mental Well-being Scale (WEMWBS): development and UK validation. Health Qual Life Outcomes. 2007;5:63; doi:10.1186/1477-7525-5-63.

24. Lang G, Bachinger A. Validation of the German Warwick-Edinburgh Mental Well-Being Scale (WEMWBS) in a community-based sample of adults in Austria: a bi-factor modelling approach. J Public Health.

2017;25:135-146; doi:10.1007/s10389-016-0778-8.

Page 20/22 
25. Idler EL, Benyamini Y. Self-rated health and mortality: a review of twenty-seven community studies. J Health Soc Behav. 1997;38:21; doi:10.2307/2955359.

26. Fayers PM, Hays RD, editors. Assessing quality of life in clinical trials: methods and practice. 2nd ed. Oxford: Oxford Univ. Press; 2005.

27. Venables WN, Ripley BD. Modern applied statistics with S. New York: Springer; 2002.

28. Fox J, Weisberg S. An R companion to applied regression. Thousand Oaks: Sage; 2019.

29. Sibley CG, Greaves LM, Satherley N, Wilson MS, Overall NC, Lee CHJ, et al. Effects of the COVID-19 pandemic and nationwide lockdown on trust, attitudes toward government, and well-being. Am Psychol. 2020; doi:10.1037/amp0000662.

30. Hobfoll SE. Conservation of resources: a new attempt at conceptualizing stress. Am Psychol. 1989;44:513; doi:10.1037/0003-066X.44.3.513.

31. Hobfoll SE, Halbesleben J, Neveu J-P, Westman M. Conservation of resources in the organizational context: the reality of resources and their consequences. Annu Rev Organ Psychol Organ Behav. 2018;5:103-128; doi:10.1146/annurev-orgpsych-032117-104640.

32. Ahmed MZ, Ahmed O, Aibao Z, Hanbin S, Siyu L, Ahmad A. Epidemic of COVID-19 in China and associated psychological problems. Asian J Psychiatr. 2020;51:102092; doi:10.1016/j.ajp.2020.102092.

33. Carstensen LL, Fung HH, Charles ST. Socioemotional selectivity theory and the regulation of emotion in the second half of life. Motiv Emot. 2003;27:103-123; doi:10.1023/A:1024569803230.

34. Podsakoff PM, MacKenzie SB, Lee J-Y, Podsakoff NP. Common method biases in behavioral research: a critical review of the literature and recommended remedies. J Appl Psychol. 2003;88:879-903; doi:10.1037/0021-9010.88.5.879.

35. Larsen MV, Petersen MB, Nyrup J. Do survey estimates of the public's compliance with COVID-19 regulations suffer from social desirability bias? 2020; doi:10.31234/osf.io/cy4hk.

36. Emmons RA, Diener E. Personality correlates of subjective well-being. Pers Soc Psychol Bull. 1985;11:89-97; doi:10.1177/0146167285111008.

37. McCauley M, Minsky S, Viswanath K. The H1N1 pandemic: media frames, stigmatization and coping. BMC Public Health. 2013;13:1116; doi:10.1186/1471-2458-13-1116.

38. Anglim J, Horwood S, Smillie LD, Marrero RJ, Wood JK. Predicting psychological and subjective well-being from personality: a meta-analysis. Psychol Bull. 2020;146:279-323; doi:10.1037/bul0000226.

39. Tonkin K, Malinen S, Näswall K, Kuntz JC. Building employee resilience through wellbeing in organizations. Num Resour Dev Q. 2018;29:107-124; doi:10.1002/hrdq.21306.

40. Jahoda M. Employment and unemployment: a social-psychological analysis. Cambridge: Cambridge University Press; 1982.

41. Kramer A, Kramer KZ. The potential impact of the Covid-19 pandemic on occupational status, work from home, and occupational mobility. J Vocat Behav. 2020:103442; doi:10.1016/j.jvb.2020.103442.

42. Wendsche J, Lohmann-Haislah A. A meta-analysis on antecedents and outcomes of detachment from work. Front Psychol. 2016;7:2072; doi:10.3389/fpsyg.2016.02072.

43. Demerouti E, Mostert K, Bakker AB. Burnout and work engagement: a thorough investigation of the independency of both constructs. J Occup Health Psychol. 2010;15:209-222; doi:10.1037/a0019408. 


\section{Supplementary Files}

This is a list of supplementary files associated with this preprint. Click to download.

- SurveyEN.pdf 